\title{
LA PEQUEÑA AgRICULTURA CAMPESINA Y FAMILIAR: CONSTRUYENDO UNA PROPUESTA DESDE LA SOCIEDAD
}

\author{
Peasant and Family Agriculture: \\ Building a Social Society Proposal
}

\section{Héctor Robles Berlanga ${ }^{1}$}

Resumen: El texto aborda la importancia de los pequeños productores y tiene como propósito contribuir a que las y los campesinos sean revalorizados por la sociedad y fortalecidos por las políticas públicas, reconociéndoles el papel central que juegan en la economía, la producción de alimentos saludables y la conservación del medio ambiente en el país.

A lo largo del escrito se explican los motivos para poner en el centro de atención a la agricultura de pequeña escala: 1) la importancia que tienen estos productores para el país; 2) los signos de agotamiento que presenta el campo mexicano, reflejados en un estancamiento de la productividad, competitividad y rentabilidad; 3) la ineficiencia en el gasto publico dirigido al sector rural, y 4) los programas en favor de la agricultura a pequeña escala se han implementado en varios países de América Latina y el mundo.

Finalmente, se incluyen líneas generales para el diseño de un programa dirigido a los pequeños productores en localidades de alta y muy alta marginación para que aumenten sus ingresos obtenidos a través de sus actividades económicas agropecuarias.

Palabras clave: pequeña agricultura, políticas públicas.

${ }^{1}$ División de Ciencias Sociales y Humanidades /Departamento de Política y Cultura Red Gestión Territorial para el Desarrollo Rural Sustentable.

Correo electrónico: 55pajaro55@gmail.com

Fecha de recepción: 2405 16; Fecha de aceptación: 271016.

(cc) EY-Nc-ND Páginas 46-83. 
Abstract: This paper addresses the importance of peasants and seeks to contribute for social and public recognition of the central role they play in Mexican economy, in healthy food production and environmental conservation, as well as to develop public polices to revalue and strengthen them.

The text points out the reasons to focus on small-scale agriculture: 1) the importance of small producers in Mexico, 2) the signs of exhaustion of Mexican countryside, reflected in stagnated productivity, low competitiveness and profitability, 3) the inefficiency of public spending for rural sectors; 4) the new public polices implemented by several countries of Latin America and the world to benefit small-scale agriculture.

Finally it contains a general design guideline for a peasant public policy in highly and very highly marginalized areas in order for them to increase income by agricultural economic activities.

Keywords: small-scale agriculture, public policies.

\section{Consideraciones generales}

El presente documento es producto de mi participación en tres espacios: en La Campaña Valor al Campesino; en el Centro Latinoamericano para el Desarrollo Rural (RIMISP), y en la Red de Gestión Territorial para el Desarrollo Rural (RED).

El primero tiene como propósito contribuir a que las y los campesinos sean revalorizados y fortalecidos por las políticas públicas y por la sociedad, reconociéndoles el papel central que juegan en la economía, la producción de alimentos saludables y la conservación del medio ambiente en el país; RIMISP promueve que el gobierno mexicano cuente con una política dirigida a los pequeños productores, y la RED somos un grupo de investigadores, especialistas y consultores, enfocado a analizar temas estratégicos en políticas públicas para la gestión territorial y el desarrollo rural. Las ideas vertidas en el presente documento rescatan las reflexiones que se realizan en esos espacios y de alguna manera lo que se plantea es resultado de un esfuerzo colectivo. 
Motiva poner en el centro de atención a la agricultura de pequeña escala por cuatro razones fundamentales: i) la importancia que tienen estos productores para el país; ii) los signos de agotamiento que presenta el campo mexicano, reflejados en un estancamiento de la productividad, competitividad y rentabilidad; iii) la ineficiencia en el gasto publico dirigido al sector rural, y iv) los programas implementados en varios países de América Latina y el mundo en favor de la agricultura en pequeña escala.

Las razones para poner en el centro de atención a la pequeña agricultura son, como lo señala la Organización de las Naciones Unidas para la Alimentación y la Agricultura (FAO, 2014) en el Año Internacional de la Agricultura Familiar 2014:

- La agricultura familiar y a pequeña escala están ligadas de manera indisociable a la seguridad alimentaria mundial.

- La agricultura familiar rescata los alimentos tradicionales, contribuyendo a una dieta equilibrada, a la protección de la biodiversidad agrícola del mundo y al uso sostenible de los recursos naturales.

- La agricultura familiar representa una oportunidad para dinamizar las economías locales, especialmente cuando se combina con políticas específicas destinadas a la protección social y al bienestar de las comunidades.

La importancia de la pequeña agricultura va más allá de nuestro país, como lo revelan estas cifras:

-Estadísticas comparables recopiladas para 81 países — que implican dos terceras partes de la población mundial y $38 \%$ de la superficie agrícola - muestran que $73 \%$ del total de explotaciones cuenta con menos de una hectárea de tierra y $85 \%$ con menos de dos hectáreas (HLPE, 2013: 7-11).

- Se estima que 500 millones de pequeños productores agrícolas en todo el mundo sostienen a unos dos mil millones de personas, es decir, un tercio de la población global. Además de representar un alto porcentaje de la producción agrícola mundial, esto incide en los medios, la calidad de vida y la seguridad alimentaria de millones de familias rurales. No existe razón para creer que esta posición cambie 
de manera sustancial en el corto y mediano plazo (Aserca, en http:// www.infoaserca.gob.mx/claridades/revistas/244/ca244-7.pdf).

- En el futuro, se necesitará un sistema agrícola que produzca alrededor de 70\% (FAO, 2009) más de alimentos para abastecer a los nueve mil millones de personas que habitarán el planeta en 2050; que provea alimentos para una nutrición adecuada; que aumente los niveles y la capacidad de recuperación de los ingresos y del empleo para la mayoría de los pobres del mundo (75\% vive en áreas rurales y depende en gran medida de la agricultura como sustento); que entregue servicios ambientales — tales como la captura del carbono, la gestión de las cuencas hidrográficas y la preservación de la biodiversidad—, y que utilice más eficientemente los limitados recursos hídricos y del suelo (BM, 2014).

\section{Importancia de la pequeña agricultura}

La pequeña unidad de producción agropecuaria y forestal es predominante en el campo mexicano. De acuerdo con distintos organismos multinacionales como la Organización de las Naciones Unidas para la Alimentación y la Agricultura (FAO), Instituto Interamericano de Cooperación para la Agricultura (IICA) y Banco Mundial (BM) e investigadores del sector agropecuario, la pequeña agricultura tiene una enorme importancia en la economía agropecuaria de los países. Como lo reporta el Censo Agrícola, Ganadero y Forestal 2007 que levantó el Instituto Nacional de Estadística y Geografía (Inegi), la pequeña unidad de producción es especialmente importante en México: de las 4 millones 69 mil 938 Unidades de Producción (UP) con actividad agropecuaria o forestal, $67.8 \%$ es menor o igual a 5 hectáreas (Inegi, 2007).

Cuadro 1. Unidades de Producción totales y con actividad agropecuaria y forestal por tamaño de predio.

\begin{tabular}{lcccccc}
\hline & & & \multicolumn{3}{c}{ Con actividad agropecuaria } \\
\cline { 4 - 6 } & & & \multicolumn{3}{c}{ y forestal } & \\
\cline { 4 - 5 } Tamaño de predio & UP & Hectáreas & UP & $\%$ & Hectáreas & $\%$ \\
\hline Hasta 1 ha & \multirow{2}{*}{$1,533,327$} & 992,890 & $1,125,020$ & 27.63 & 765,865 & 1.12
\end{tabular}




\begin{tabular}{|c|c|c|c|c|c|c|}
\hline $\begin{array}{l}\text { Más de } 1 \text { hasta } \\
2 \text { ha }\end{array}$ & 882,389 & $1,539,236$ & 674,831 & 16.58 & $1,210,004$ & 1.77 \\
\hline $\begin{array}{l}\text { Más de } 2 \text { hasta } \\
5 \text { ha }\end{array}$ & $1,270,515$ & $4,511,651$ & 961,931 & 23.64 & $3,457,323$ & 5.05 \\
\hline $\begin{array}{l}\text { Más de } 5 \text { hasta } \\
10 \text { ha }\end{array}$ & 807,668 & $6,093,711$ & 595,064 & 14.62 & $4,513,579$ & 6.60 \\
\hline $\begin{array}{l}\text { Más de } 10 \text { hasta } \\
20 \text { ha }\end{array}$ & 490,310 & $7,279,716$ & 348,666 & 8.57 & $5,226,142$ & 7.64 \\
\hline $\begin{array}{l}\text { Más de } 20 \text { hasta } \\
50 \text { ha }\end{array}$ & 319,627 & $10,077,746$ & 217,310 & 5.34 & $6,865,140$ & 10.03 \\
\hline $\begin{array}{l}\text { Más de } 50 \text { hasta } \\
100 \text { ha }\end{array}$ & 120,722 & $8,702,408$ & 77,963 & 1.92 & $5,623,535$ & 8.22 \\
\hline $\begin{array}{l}\text { Más de } 100 \text { hasta } \\
1000 \text { ha }\end{array}$ & 111,776 & $29,291,866$ & 62,524 & 1.54 & $16,157,343$ & 23.61 \\
\hline $\begin{array}{l}\text { Más de } 1000 \\
\text { hasta } 2500 \text { ha }\end{array}$ & 7,364 & $11,620,392$ & 3,772 & 0.09 & $5,967,642$ & 8.72 \\
\hline Más de 2500 ha & 5,147 & $32,239,493$ & 2,857 & 0.07 & $18,649,030$ & 27.25 \\
\hline Total & $5,548,845$ & $112,349,109$ & $4,069,938$ & 100 & $68,435,603$ & 100 \\
\hline
\end{tabular}

Fuente: INEGI. Censo Agrícola, Ganadero y Forestal 2007

Es la unidad de producción que más ha crecido en el pais. Las UP menores a 5 hectáreas, en lugar de disminuir en el transcurso del tiempo como se pretendió con muchas políticas agrarias, se han multiplicado; su crecimiento en 80 ańos fue de $708.7 \%$, al pasar de 332 mil que existían en 1930, a 2.6 millones de unidades en 2007. Tener menos de cinco hectáreas distingue a los productores de nuestro país (íbid.).

Cuadro 2. Comparativo Unidades de Producción con menos de 5 hectáreas, 1930-2007.

\begin{tabular}{crrr}
\hline Año & \multicolumn{1}{c}{ UP } & Menos de 5 ha & \multicolumn{1}{l}{$\%$} \\
\hline 1930 & 614,101 & 332,439 & 54.1 \\
1940 & 858209 & 567,874 & 66.1 \\
1950 & $1,383,212$ & $1,004,839$ & 72.6
\end{tabular}




\begin{tabular}{rrrr}
1960 & $1,220,324$ & 928,757 & 76.1 \\
1970 & 846,994 & 567,129 & 67.0 \\
1980 & $3,062,950$ & $1,792,654$ & 58.5 \\
1990 & $3,504,510$ & $2,114,622$ & 60.3 \\
2007 & $4,069,938$ & $2,688,611$ & 67.8 \\
\hline
\end{tabular}

Fuente: Inegi. I, II, III, IV, V, VI, VII y VIII Censo Agrícola, Ganadero y Forestal

Produce una parte muy significativa de nuestros alimentos y tiene una fuerte presencia en la producción de maíz y frijol. A pesar de sus condiciones precarias para producir y a la falta de apoyos económicos gubernamentales, la pequeńa agricultura tiene una enorme importancia, pues representa 39\% de la producción agropecuaria nacional (Gobierno de la República, 2013). Además, siete de cada diez productores que siembran maíz — blanco y amarillo- y seis de cada diez de frijol tienen menos de 5 ha (Inegi, 2007). El maíz y frijol son los principales cultivos en nuestra dieta, los encontramos prácticamente en todo el país, en los distintos climas, en condiciones orográficas contrastantes y con sistemas de producción muy diversos entre sí.

Cuadro 3. Productores de maíz amarillo y blanco y frijol por tamaño de predio.

\begin{tabular}{|c|c|c|c|}
\hline Cultivo & Predio & $U P$ & $\%$ \\
\hline & Hasta 5 ha & 374,372 & 73.4 \\
\hline \multirow[t]{4}{*}{ Maíz amarillo } & Más de 5 hasta 10 ha & 66,152 & 13.0 \\
\hline & Más de 10 ha & 69,787 & 13.7 \\
\hline & Total & 510,311 & 100 \\
\hline & Hasta 5 ha & $1,610,275$ & 70.5 \\
\hline \multirow[t]{3}{*}{ Maíz blanco } & Más de 5 hasta 10 ha & 336,272 & 14.7 \\
\hline & Más de 10 ha & 337,082 & 14.8 \\
\hline & Total & $2,283,629$ & 100 \\
\hline
\end{tabular}




\begin{tabular}{|c|c|c|c|}
\hline \multirow{4}{*}{ Frijol } & Hasta 5 ha & 377,227 & 60.62 \\
\hline & Más de 5 hasta 10 ha & 121,394 & 19.51 \\
\hline & Más de 10 ha & 123,643 & 19.87 \\
\hline & Total & 622,264 & 100 \\
\hline
\end{tabular}

Fuente: Inegi. Censo Agrícola, Ganadero y Forestal 2007

Generan la mayor parte del empleo agropecuario. Las UP menores a 5 hectáreas generan $56.8 \%$ de los empleos del sector, tanto familiares como contratados. Si les sumamos las UP hasta 10 hectáreas llegan a $74.1 \%$ (íbid.). Es decir, tres de cada cuatro empleos se localizan en la pequeña y mediana agricultura, mientras que en las UP mayores o iguales a 100 ha sólo contratan 7.9\% de los trabajadores agrícolas.

Cuadro 4. Empleo familiar y Contratado por tamaño de predio.

\begin{tabular}{|c|c|c|c|c|c|c|}
\hline Tamaño de predio & $\begin{array}{l}\text { Trabajo } \\
\text { familiar }\end{array}$ & $\%$ & Contratado & $\%$ & Total & $\%$ \\
\hline Hasta 2 ha & $1,786,586$ & 50,9 & $1,584,556$ & 30,8 & $3,371,142$ & 39,0 \\
\hline Más de 2 hasta 5 ha & 779,256 & 22,2 & $1,334,419$ & 26,0 & $2,113,675$ & 24,4 \\
\hline Más de 5 hasta 20 ha & 692,538 & 19,7 & $1,434,677$ & 27,9 & $2,127,215$ & 24,6 \\
\hline Más de 20 hasta 50 ha & 153,517 & 4,4 & 380,542 & 7,4 & 534,059 & 6,2 \\
\hline Más de 50 hasta 100 ha & 54,801 & 1,6 & 174,631 & 3,4 & 229,432 & 2,7 \\
\hline Más de 100 hasta 1000 ha & 41,319 & 1,2 & 207,378 & 4,0 & 248,697 & 2,9 \\
\hline Más de 1000 hasta 2500 ha & 1,715 & 0,0 & 13,382 & 0,3 & 15,097 & 0,2 \\
\hline Más de 2500 ha & 820 & 0,0 & 10,202 & 0,2 & 11,022 & 0,1 \\
\hline Total & $3,510,552$ & 100 & $5,139,787$ & 100 & $8,650,339$ & 100 \\
\hline
\end{tabular}

Fuente: Inegi. Censo Agrícola, Ganadero y Forestal 2007

Importantes abastecedores de la agroindustria. En la revisión documental que se realizó del estudio "Dinámicas del mercado de la tierra en América Latina y el Caribe: concentración y extranjerización” se encontraron “... distintos tipos de agroindustria que se relacionan de diversas maneras con los productores: a) agroindustrias donde sus socios no son 
propietarios de tierra y sólo compran materias primas; b) grandes y medianos productores tecnificados que son parte de la empresa y operan como empresarios y productores; c) empresas que establecen, con los productores primarios, convenios de abastecimiento de materias primas, y d) productores de pequeña escala, que venden a intermediarios su producción para abastecer a la agroindustria... Uno de los resultados que resaltan del estudio es que la mayoría de los productores ligados a la agroindustria son minifundistas. Los maiceros tienen 2.7 hectáreas en promedio por productor; los productores de caña de azúcar, 5 ha; hortalizas, 6 ha; frutas 5 ha o menos; café, 1,9 ha; cebada, 6 ha, y tabaco 2 ha" (FAO, 2012).

La pequeña producción mantiene vivo el legado de las y los antiguos pobladores que desde hace más de diez mil años iniciaron en esta región de la Tierra el cultivo de maíz, calabaza, frijol, chile, jitomate, aguacate, vainilla, papaya, guayaba y otros alimentos que en conjunto representan $16 \%$ de las especies que hoy consume la humanidad (Sarukhán et al., 2008).

La labor de las y los pequeños productores permite combatir el mayor problema de salud pública en México: la epidemia de obesidad, que se ha incrementado en los 30 años recientes. La incidencia de sobrepeso y obesidad en mujeres adultas aumentó de 35\% en 1988 a $73 \%$ en 2012 La diversidad de cultivos es indispensable para el fomento de dietas variadas que contribuyan a enfrentar la desnutrición y el sobrepeso (Ensanut, 2012).

La producción campesina de alimentos es la base del reconocimiento a la cocina tradicional mexicana como Patrimonio Cultural Inmaterial de la Humanidad. Reconocida por la Unesco en 2010 por ser "un modelo cultural completo que comprende actividades agrarias, prácticas rituales, conocimientos prácticos antiguos, técnicas culinarias y costumbres y modos de comportamiento comunitarios ancestrales (Unesco, 2010).

\section{El campo mexicano presenta signos de agotamiento}

En el Programa Nacional de Desarrollo Agropecuario, Pesquero y Alimentario 2013-2018 (PNDAPA) se afirma que el campo mexicano 
presenta signos de agotamiento reflejados en un estancamiento de la productividad, competitividad y rentabilidad (DOF, 13-12-2013). Algo similar se dice en el Programa para Democratizar la Productividad 2013-2018 (PDP) al señalarse que respecto a los productores rurales, mientras que el valor agregado por trabajador en el sector agrícola mexicano aumentó en 52\% entre 1980 y 2010, en Brasil, Chile y China creció 3.8, 2.6 y 3.0 veces, respectivamente (DOF 30-08-2013).

Entre las distintas razones que se dan para explicar la baja productividad se tiene:

a) Bajo crecimiento. Entre 2000 y 2012, el PIB de las actividades primarias registró un crecimiento promedio anual de $1.4 \%$ - agricultura $1.4 \%$, ganadería $1.8 \%$, y pesca y acuacultura $0 \%$ - mientras que la economía nacional creció a una tasa de $2.1 \%$.

b) Baja disponibilidad de agua de riego. Más de 60\% del país se localiza en zonas áridas o semiáridas, el cielo alimenta las reservas hídricas con poco más de un millón y medio de metros cúbicos de agua de lluvia al año y $77 \%$ de este recurso es utilizado en la agricultura, con grandes deficiencias en su uso y suministro. De la superficie agrícola $74 \%$ se cultiva en temporal, por lo que la producción está más expuesta a los efectos climáticos — sequías, inundaciones, heladas, entre otros_-; sólo $26 \%$ de la superficie cultivada cuenta con riego (OCDE, 2011). Además, en 2012 sólo 3.3 millones de hectáreas de tierras de riego habían sido modernizadas y tecnificadas, 55\% de la superficie total de riego en el país (DOF 13-12-2013).

c) Economía ambientalmente no sustentable. De acuerdo con la Secretaría de medio ambiente y recurn ¿̨os naturales (Semarnat), el crecimiento del país ha estado lejos de ser ambientalmente sustentable. Paralelamente al aumento del producto interno bruto (PIB) crecieron las emisiones de bióxido de carbono $\left(\mathrm{CO}_{2}\right)-\mathrm{el}$ principal gas responsable del efecto invernadero-, la generación de residuos de distintos tipos y la descarga de aguas residuales, a la vez que la cubierta de bosques y selvas se redujo. Esta pérdida y deterioro del capital natural viene acompañada de importantes costos económicos. Según cálculos del Instituto Nacional de Estadística y Geografía, el costo total del agotamiento y la 
degradación ambiental (CTADA) representó 6.5\% del Producto Interno Bruto en 2011.

d) Cambio climático. Gran parte del territorio mexicano es vulnerable al estrés hídrico, situación que podría agravarse por el cambio climático. Las cambiantes condiciones climáticas se reflejarán en sequías, heladas fuera de época, inundaciones por altas precipitaciones, y mayor presencia de plagas y enfermedades. Todos estos factores generan incertidumbre entre los productores agropecuarios y forestales. Se debe recordar que $78 \%$ de las UP censadas en 2007 reportó como el principal problema aspectos relacionados con las cuestiones climáticas.

e) Baja capacidad de respuesta para incorporar los avances tecnológicos. En México, son débiles los procesos de innovación tecnológica entre la gran mayoría de los productores agropecuarios y forestales. Una de las causas es la baja inversión en ciencia y tecnología para el sector agroalimentario, que no alcanza $0.6 \%$ del producto sectorial (Maluf, 2010). Además, los temas de extensión y transferencia tecnológica son rudimentarios, y hay pocas asociaciones de productores que estén jugando un rol de liderazgo en procesos de innovación tecnológica.

Los factores anteriormente señalados conducen a un desarrollo económico y social sectorial que claramente está lejos del potencial del país:

- Baja productividad. La productividad en las actividades primarias presentó una tasa media anual de crecimiento de sólo $1.4 \%$ entre 2000 y 2012 (OCDE, 2011).

- Déficit en la balanza comercial. Si bien México es el octavo productor mundial de agroalimentos y las exportaciones agroalimentarias muestran un gran dinamismo con ingresos superiores a las remesas y al turismo, la producción nacional es insuficiente para abastecer la demanda interna de algunos alimentos básicos. En 2012 México importó 32\% del consumo interno al requerir 10 productos básicos -maíz, trigo, frijol, arroz, soya, sorgo, carne de bovino, porcino y ave, y huevo- - Por ejemplo, adquirió $79 \%$ del consumo doméstico de arroz, $93 \%$ de oleaginosas, $58 \%$ de trigo y $82 \%$ de maíz amarillo 
para consumo pecuario e industrial. Más allá de lo que ello implica desde el objetivo de seguridad alimentaria, es indudable que México tiene el potencial de ser competitivo en varios de los rubros mencionados.

- Pobreza persistente. En los últimos 20 años muchos países de América Latina han reducido la pobreza rural en forma notable, lo que lamentablemente no ha ocurrido en México. Según el Consejo Nacional de Evaluación de la Política de Desarrollo Social (Coneval), en 2012 el $61.6 \%$ de la población rural vivía en condición de pobreza y $21.5 \%$ en pobreza extrema — tasas de incidencia 25 y 16 puntos porcentuales más altas que las cifras correspondientes al sector urbano-. En el mismo año, 31\% de la población rural tenía carencia de acceso a la alimentación, 12 puntos porcentuales por encima que la población urbana. Lo más preocupante es que la situación no ha cambiado de manera significativa si comparamos los años 2012 y 1992.

\section{Ineficiencia en el gasto público dirigido al sector rural}

Baja cobertura de los programas que integran el Programa Especial Concurrente para el Desarrollo Rural Sustentable (PEC). A pesar de que el PEC lo conforman más de 150 componentes o programas, ${ }^{2}$ son muy pocos los que tienen cobertura en la mayoría de los municipios. De los 80 programas analizados, sólo nueve tienen presencia a nivel nacional, siete son de la vertiente Social —Oportunidades, Pensión para Adultos Mayores 70 y Más, Programa de Apoyo Alimentario y el abasto operado por Diconsa, Programa de Abasto Social de leche en sus dos modalidades, Programa para el Desarrollo de Zonas Prioritariasy dos de la vertiente de Competitividad, específicamente Procampo —ahora Proagro- y Diésel Agropecuario — que desapareció en 2014-. Por el contrario, la mayoría de los programas no reportaron beneficiarios en 1,718 municipios.

\footnotetext{
${ }^{2}$ Referido al presupuesto, la Secretaría de Hacienda y Crédito Público define "programas" y a su interior "componentes". Por ejemplo, los componentes Procampo, Fomento Café y Agricultura de Autoconsumo, Apoyo a Pequeños Productores hasta 3.0 ha, eran parte del Programa de Apoyo al Ingreso Agropecuario. Los productores conocen los componentes como programas, pues de esa forma acceden a los apoyos.
} 
Gráfica 1. Baja cobertura de los programas.

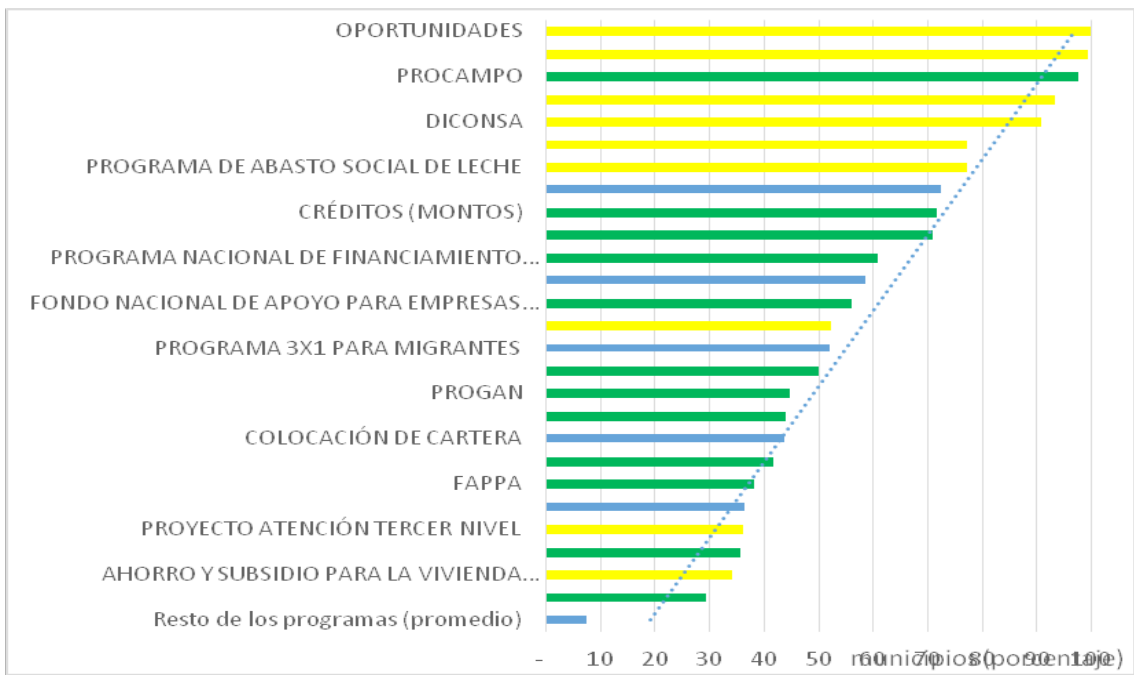

Fuente: Elaboración propia con información del Presupuesto de Egresos de la Federación 2013-2016 y Proyecto de Presupuesto de Egresos de la Federación 2017

La politica hacia el sector rural tiene una orientación social y no productiva. Al comparar los montos ejercidos de las vertientes Competitividad y Social por entidad federativa se encontró que en 14 de 16 entidades del norte del país los subsidios referidos a Competitividad representaron más de $52 \%$ del presupuesto ejercido; mientras que en el centro y sur del país los apoyos a Social representaron 58\% o más del presupuesto ejecutado, cuando en estas regiones del país se encuentra el mayor número de productores y la mayoría de los ejidos y comunidades. A nivel local, en 1,570 municipios son más importantes los recursos que provienen de Sedesol; mientras que en 358 predominan los de Sagarpa. 
Mapa 1. Comparativo del presupuesto ejercido Sagarpa-Sedesol.

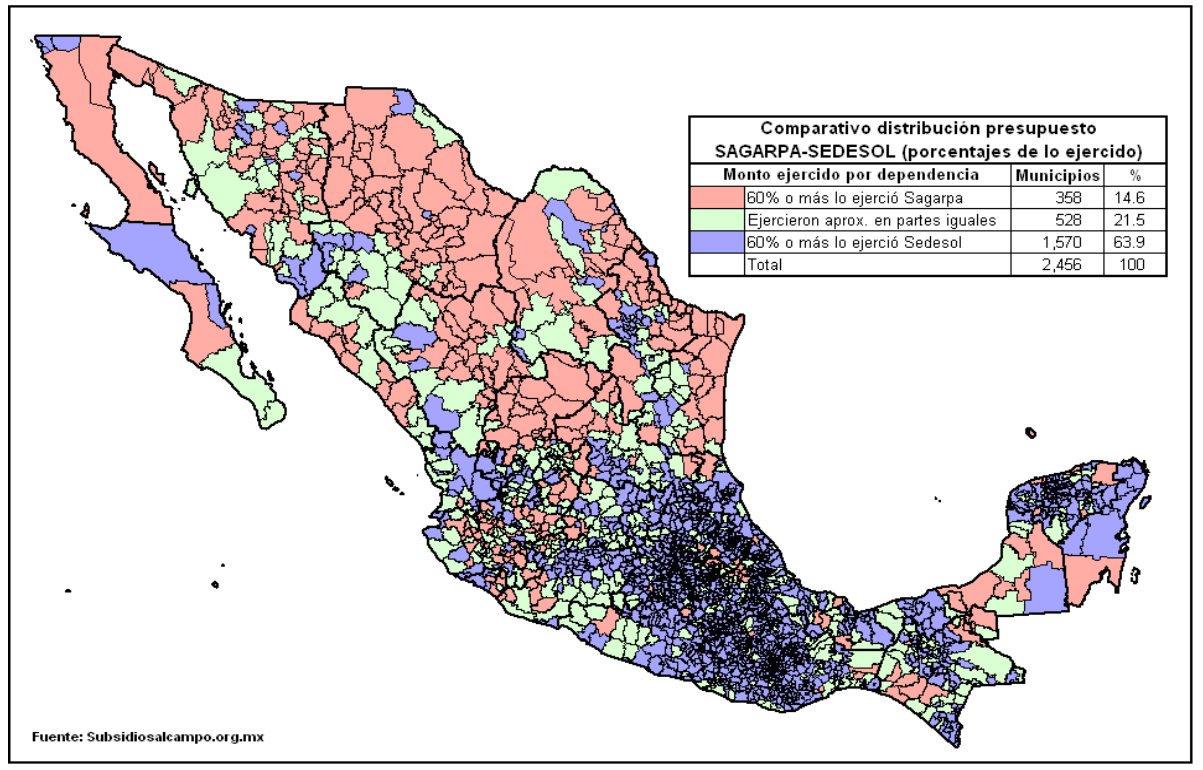

Fuente: Elaboración propia con información del Presupuesto de Egresos de la Federación 2013-2016 y Proyecto de Presupuesto de Egresos de la Federación 2017

Lo anterior se observa también en las zonas marginadas: en los municipios de Muy Alta marginación, $67.7 \%$ del presupuesto ejercido correspondió a la vertiente Social, y sólo $24.3 \%$ a la de Competitividad; mientras que en los municipios de Muy Baja marginación esa relación fue de 26.2 respecto a $25.8 \%$.

Por su parte, en los municipios indígenas se destinó $68.3 \%$ del presupuesto a Social y sólo $23.8 \%$ a Competitividad.

Estas cifras muestran que en el sector rural se pretende combatir la pobreza sobre la base de programas asistenciales, y no generando mejores ingresos y empleo a partir del estímulo a las actividades productivas locales. 
Desigualdad y concentración de la vertiente productiva y financiera. La política pública de apoyo a la producción se encuentra altamente concentrada en muy pocos estados y en muy pocos productores. Cinco entidades del norte del país - Sinaloa, Chihuahua, Tamaulipas, Sonora y Jalisco-, que contienen 9\% de las UP que existen en México, concentraron $38.9 \%$ del presupuesto de la vertiente de Competitividad, $43.6 \%$ del recurso operado por Finrural, y 42.6\% del crédito FIRA; mientras que a 16 entidades del país - la mayoría del centro y surdonde se localizan 42.6\% de UP, sólo les llegó 26.2, 20.9 y $17.1 \%$ de dichos apoyos, respectivamente. Al calcular el per cápita del presupuesto ejercido en competitividad y financiamiento entre el número total de UP resulta que en las cinco entidades del norte es de 100,614.00 pesos, mientras que para las 16 entidades de 19,405.00 pesos, cinco veces menos que en los estados del norte. Otro dato: en 704 municipios, FIRA no otorgó créditos. La concentración de los recursos en las regiones o entidades más productivas profundiza las inequidades sociales y económicas.

Gráfica 2. Desigualdad y concentración de la vertiente productiva y financiera. 25,000

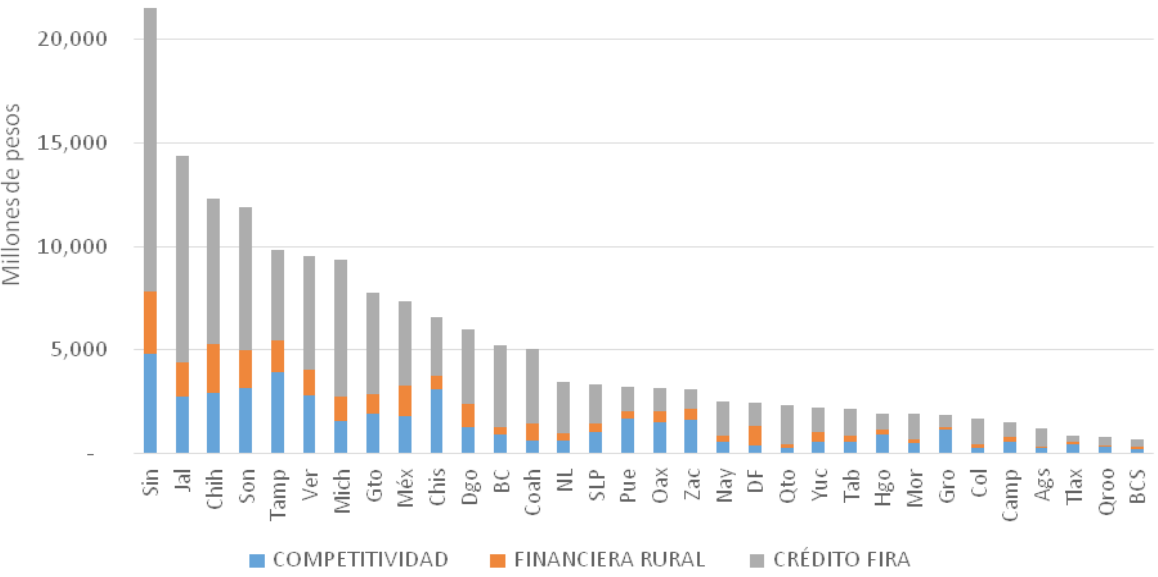

Fuente: Elaboración propia con información del Presupuesto de Egresos de la Federación 2013-2016 y Proyecto de Presupuesto de Egresos de la Federación 2017 
Gráfica 3. Regresividad de algunos programas productivos y financieros.

Procampo (Proagro Productivo).

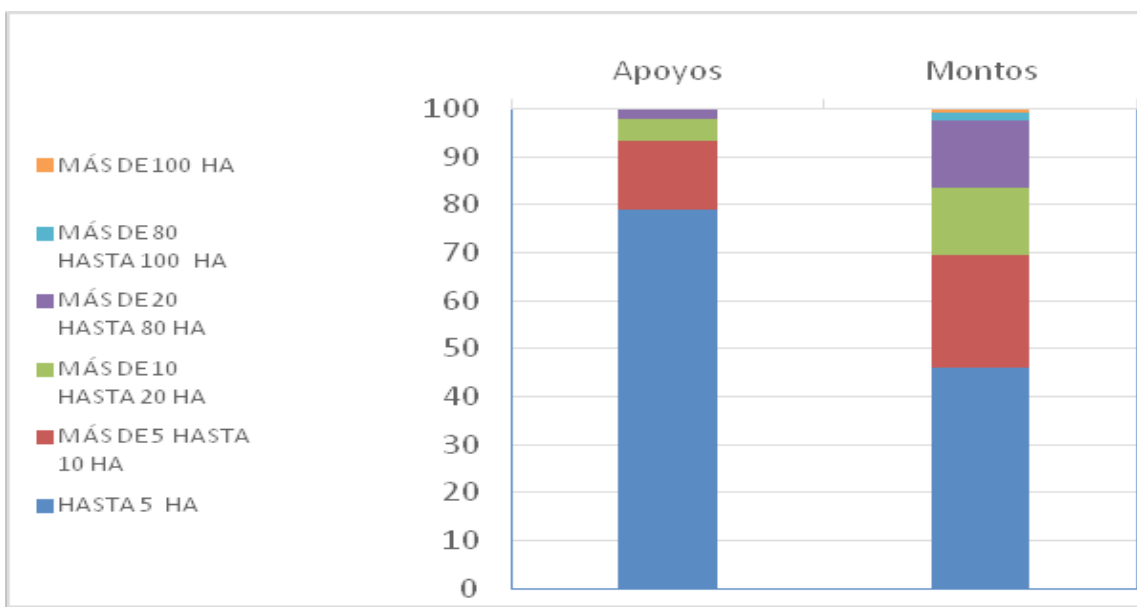

Progan (Programa de Producción Pecuaria Sustentable y Ordenamiento Ganadero y Apícola).

\begin{tabular}{|c|c|c|c|}
\hline & & Apoyos & Montos \\
\hline & 100.0 & & \\
\hline mÁSDE500 CABEZAS & 90.0 & & \\
\hline MÁS DE 300 HASTA 500 & 80.0 & & \\
\hline CABEZAS & 70.0 & & \\
\hline $\begin{array}{l}\text { MÁSDE } 100 \text { HASTA } 300 \\
\text { CABEZAS }\end{array}$ & 60.0 & & \\
\hline 口MÁS DE 50 HASTA 100 & 50.0 & & \\
\hline CABEZAS. & 40.0 & & \\
\hline -MÁS DE 20 HASTA 50 & & & \\
\hline CABEZAS & 30.0 & & \\
\hline \multirow[t]{3}{*}{-HASTA 20 CABEZAS } & 20.0 & & \\
\hline & 10.0 & & \\
\hline & - & & \\
\hline
\end{tabular}


FIRA (Fideicomisos Instituidos en Relación con la Agricultura). Programa descuentos.

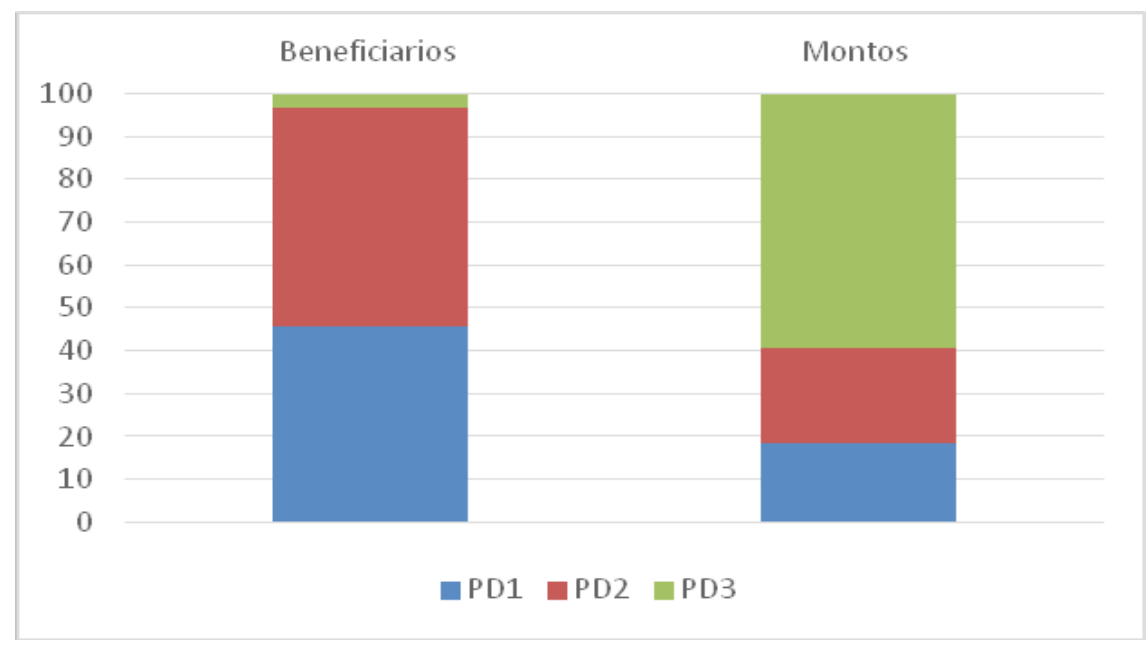

Aserca (Agencia de Servicios a la Comercialización y Desarrollo de Mercados Agropecuarios). Programa coberturas y agricultura por contrato.

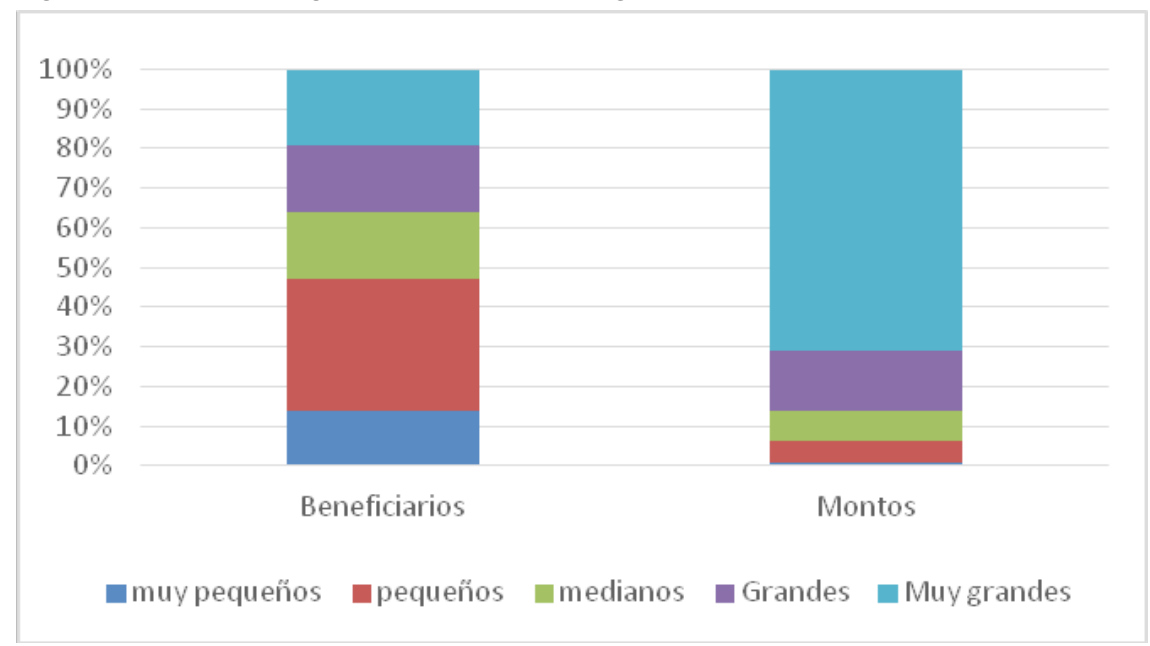

Fuente: Elaboración propia con información del Presupuesto de Egresos de la Federación 2013-2016 y Proyecto de Presupuesto de Egresos de la Federación 2017 
La población marginada e indigena es la menos beneficiada. El monto per cápita promedio por beneficiario del PEC fue 4,373 pesos. Por debajo de este promedio se encuentran los productores de los municipios de Muy Alta marginación con 3,581 pesos y los productores de los municipios indígenas con 3,747 pesos. Si la comparación se hiciera con respecto a los municipios de Muy Baja marginación y los municipios sin población indígena el resultado sería de 3,423 y 7,666 pesos, respectivamente.

Gráfica 4. La población indígena es la menos favorecida en el presupuesto para el campo.

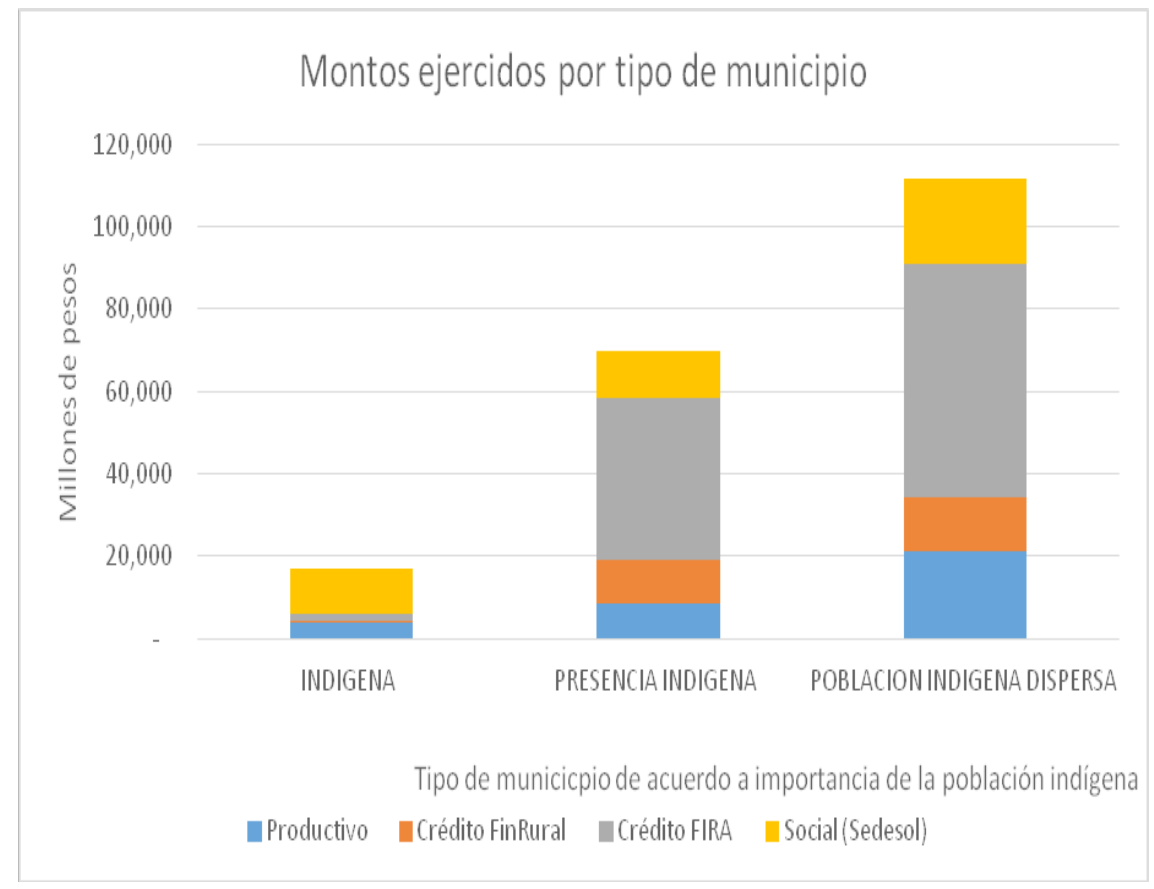

Fuente: Elaboración propia con información del Presupuesto de Egresos de la Federación 2013-2016 y Proyecto de Presupuesto de Egresos de la Federación 2017 
$\mathrm{Al}$ analizar el ejercicio del presupuesto de la vertiente Competitividad resultó que en los municipios de Muy Alta marginación los beneficiarios recibieron en promedio 3,581 pesos, mientras que en los de Muy Baja marginación 11,295 pesos. Por su parte, en los municipios indígenas el promedio fue de 3,747 contra 8,323 pesos en los no indígenas. Además, en 1,372 municipios del país, el promedio per cápita es menor a 4 mil pesos, mientras que en 136 municipios supera los diez mil pesos. Las diferencias en la distribución de los recursos entre los distintos grupos sociales ahonda más la desigualdad social.

El presupuesto favorece a municipios con mejor Índice de Desarrollo Agropecuario (IDA). ${ }^{3}$ En los municipios de Muy Alto Índice de Desarrollo Agropecuario se ejerció 4.7\% del presupuesto PEC y $21.3 \%$ del crédito FIRA, aun cuando sólo incluyen $0.7 \%$ de UP; mientras que en los municipios de IDA Muy Bajo, en los que se encuentra 20\% de los productores, se ejerció $12.2 \%$ del PEC y sólo $1.2 \%$ del crédito otorgado por FIRA. El per cápita por Unidad resultó de 177,067 pesos en municipios de IDA Muy Alto contra 15,691 pesos en los municipios de IDA Muy Bajo. Los municipios con mejor IDA tienen mayores posibilidades de competir contra otros productores y de emprender proyectos de mayor impacto regional.

\footnotetext{
${ }^{3}$ Para mayores detalles sobre el Índice de Desarrollo Agropecuario consultar Robles, Héctor, 2007, El sector rural en el siglo XXI. Un mundo de realidades y posibilidades, CEDRSSA, México.
} 
Cuadro 5. Distribución del presupuesto por Índice de Desarrollo Agropecuario

\begin{tabular}{|c|c|c|c|c|c|c|c|}
\hline$I D A$ & $U P$ & $\begin{array}{c}U P \\
\text { promedio }\end{array}$ & Comp. & Infr. & $\begin{array}{c}M . \\
\text { Amb. }\end{array}$ & Social & $\begin{array}{c}F \\
\text { Rural }\end{array}$ \\
\hline uy alto & 29,136 & 67.81 & 23.0 & 0.2 & 1.9 & 16.0 & 58.8 \\
\hline & 152,167 & 40.84 & 30.6 & 0.7 & 2.8 & 17.5 & 48.4 \\
\hline Medio & $1,765,678$ & 23.06 & 36.4 & 1.2 & 5.0 & 34.6 & 22.8 \\
\hline & $1,307,566$ & 11.66 & 30.0 & 2.0 & 5.8 & 52.8 & 9.4 \\
\hline Muy bajo & 811,412 & 5.15 & 21.5 & 2.6 & 2.9 & 69.0 & 4.0 \\
\hline Total & $4,065,959$ & 16.81 & 31.8 & 1.4 & 4.6 & 40.5 & 21.7 \\
\hline
\end{tabular}

\begin{tabular}{|c|c|c|}
\hline$I D A$ & PEC & $\begin{array}{l}\text { Crédito } \\
\text { FIRA }\end{array}$ \\
\hline Muy alto & $5,159,024$ & $20,208,848$ \\
\hline Alto & $10,916,888$ & $20,022,532$ \\
\hline Medio & $50,563,604$ & $44,795,004$ \\
\hline Bajo & $25,166,505$ & $8,479,893$ \\
\hline Muy bajo & $12,732,029$ & $1,177,785$ \\
\hline Total & $104,538,050$ & $94,684,062$ \\
\hline
\end{tabular}

Leyenda: IDA: Indice de Desarrollo Agropecuario; UP: Unidad Productiva; Comp.: Competitividad; Infr.: Infraestructura; M. Amb.: Medio Ambiente; F. Rural: Financiera Rural; PEC: Programa Especial Concurrente para el Desarrollo Rural Sustentable.

Fuente: elaboración propia con base en solicitudes de información a Sistema Infomex, FIRA, Censo Agrícola, Ganadero y Forestal 2007, y Conapo 
Incumplimiento en la transparencia y rendición de cuentas. Si bien se avanzó con la disposición de que los padrones sean públicos, todavía hay claroscuros en la distribución de los subsidios. No existe el padrón único de los programas de Competitividad que permita observar quiénes se están beneficiando con más de un apoyo; la información se encuentra en formatos poco accesibles para el público; se detectan problemas con los datos - por ejemplo, en algunos de los reportes sobre el presupuesto no se identifica a qué municipio se transfirieron o si el beneficiario es hombre o mujer-, por mencionar algunos aspectos.

\section{Experiencia latinoamericana a favor de la agricultura de pequeña escala ${ }^{4}$}

Berdegué y Fuentealba (2014) estiman que en América Latina hay alrededor de 15 millones de pequeños productores agropecuarios. De ellos, $65 \%$ - con $25 \%$ de la tierra bajo control y uso de este tipomuestra hogares con estrategias de ingreso altamente diversificadas, en las que la agricultura juega un papel complementario principalmente a través de la producción para el autoconsumo. La producción agrícola es sin embargo un componente vital de la vida de estos hogares, sin el cual sus condiciones de pobreza e inseguridad alimentaria aumentarían considerablemente. Poco más de una cuarta parte de los pequeños productores - con la mitad de la tierra de la agricultura campesina — son hogares que participan en los mercados agroalimentarios, pero que enfrentan importantes restricciones y desafíos porque sus activos productivos son escasos, porque son poco y mal atendidos por las políticas públicas, y porque viven y trabajan en territorios que carecen de distintos tipos de bienes públicos tangibles e intangibles —zonas de selvas y bosques donde se captura agua y carbono, zonas con especies endémicas, etcétera-. El resto, poco menos de $9 \%$ de los pequeños productores — con $25 \%$ de la tierra - está plenamente vinculado a cadenas de valor orientadas a mercados dinámicos y altamente competitivos.

\footnotetext{
${ }^{4}$ Este apartado se alimenta del trabajo de Héctor Robles y Julio Berdegué, 2015, Matriz de Indicadores para Resultados del programa S266. Programa de Apoyo a Pequeños Productores, Rimisp, México.
} 
Soto Baquero et al. (2008) analizan seis países que concentran alrededor de $80 \%$ de la pequeña agricultura latinoamericana. Señalan que a través de 11 millones de UP controlan entre el 30 y el 60\% de la superficie agrícola de sus países. Los autores la tipifica en tres categorías: a) subsistencia, con 7 millones de UP -y 63 millones de hectáreas- - b) un grupo en transición con 3 millón de Unidades — 43 millones de hectáreas-, y c) un grupo de 1 millón de agricultores familiares consolidados, con 29 millones de hectáreas.

Por su parte, Schejtman y Chiriboga (2009) retoman a Soto Baquero y señalan que a pesar de la reducida disponibilidad de activos y de los relativos bajos niveles de productividad, la agricultura familiar es un importante proveedor de muchos de los alimentos básicos de consumo popular. Los autores analizan el caso de Brasil donde los pequeños productores producen $67 \%$ del frijol, $84 \%$ de la yuca, $49 \%$ del maíz y $52 \%$ de la leche. En Colombia aportan más de $30 \%$ de la producción de cultivos anuales; en Ecuador, 64\% de las papas, 85\% de las cebollas, $70 \%$ del maíz, $85 \%$ del maíz suave y $83 \%$ de la producción de carne de ovino; en Bolivia, 70\% del maíz y del arroz, la casi totalidad de las papas y la yuca; en Chile, $45 \%$ de las hortalizas de consumo interno, $43 \%$ del maíz, trigo y arroz y $40 \%$ de la carne y leche, y así sucesivamente. En términos agregados, la participación de la agricultura familiar en la producción sectorial va de $27 \%$ para Chile a $67 \%$ para Nicaragua, y la participación en el empleo fluctúa entre $60 \%$ y $80 \%$ del sector (Soto et al., 2008).

En Brasil existe una ley que reconoce a la agricultura familiar. De acuerdo con el censo agropecuario brasileño de 2006, se puede decir que la agricultura familiar está presente en todo el territorio nacional y es además un perfil de agricultura que responde por casi $85 \%$ de las fincas, aunque ocupa apenas $24.3 \%$ del área (Sánches, 2010). Institucionalmente, Brasil cuenta con un ministerio especializado en agricultura familiar y desarrollo rural -Ministerio de Desarrollo Agrario- y otro orientado a la agricultura empresarial y la agroindustria - Ministerio de Agricultura.

En Argentina, el Instituto Nacional de Tecnología Agropecuaria (INTA) crea a mediados del año 2005 el Centro de Investigación y 
Desarrollo Tecnológico para la Pequeña Agricultura Familiar (Cipaf), del cual dependen cinco Institutos especializados en la problemática de esta forma de organización, distribuidos estratégicamente en las macrorregiones del país: Noroeste Argentino, Noreste Argentino, Pampeana, Cuyo y Patagonia. Estos Institutos investigan, forman y capacitan a profesionistas y agentes de desarrollo vinculados a la agricultura familiar. Su objetivo es generar, adaptar, rescatar y validar tecnología apropiada para su desarrollo, con la finalidad de promover la generación de empleos e ingresos genuinos a nivel territorial, arraigo rural, contribuir a la soberanía y seguridad alimentaria, y posibilitar el acceso a los mercados (Ramilo, 2010).

En Bolivia se ha creado un entorno político favorable a los pueblos indígenas y las organizaciones de pequeños agricultores. Se han registrado disminuciones apreciables de la inseguridad alimentaria en el curso de dos décadas dedicadas a empoderar a los pueblos indígenas, aproximadamente $62 \%$ de la población (FAO, 2014).

Chile cuenta con un instituto especializado en agricultura familiar cuya población objetivo está definida por ley. El Instituto de Desarrollo Agropecuario (Indap) es una entidad dependiente del Ministerio de Agricultura, que cuenta con programas que se operan en forma articulada de tal forma que los pequeños agricultores accedan a un conjunto coherente y suficiente de servicios para que puedan lograr sus objetivos productivos. El presupuesto de Indap en 2015 equivale a $50 \%$ del presupuesto sectorial. La población atendida por Indap incluye desde el minifundio indígena de autoconsumo hasta los pequeños productores ligados a los circuitos de exportación, aunque los primeros son, con creces, los más numerosos, reflejando lo que sucede en la estructura agraria del país.

En Colombia está por concluir el trabajo de un grupo establecido por decisión del presidente de la República, denominado Misión para la Transformación del Campo, "Misión Rural”. Los informes ya aprobados por el gobierno nacional, a través del Departamento Nacional de Planeación, definen una ambiciosa estrategia de inclusión productiva con un muy fuerte acento en la agricultura familiar. La implementación de esta agenda de transformación del campo colombiano con foco en la 


\section{Héctor Robles Berlanga La pequeña agricultura campesina y familiar: construyendo una propuesta...}

pequeña agricultura requerirá una inversión equivalente a 1.5 puntos porcentuales del PIB nacional. Semejante inversión se justifica a juicio del gobierno colombiano por la importancia del desarrollo del sector rural en el proceso de construcción de la paz, como consecuencia de los acuerdos de las negociaciones en La Habana.

Hay aspectos comunes en las políticas internacionales más avanzadas de apoyo a la pequeña agricultura. Estos incluyen:

a) Una definición e identificación precisa de la población objetivo a nivel nacional, estatal y local.

b) Un programa con componentes coordinados y complementarios entre sí, o una única institución con programas con las mismas características, de tal forma que el productor reciba un conjunto articulado de servicios complementarios suficientes para resolver los problemas y estimular procesos de desarrollo crecientemente autosustentados.

c) Dichos componentes o programas de apoyo a la pequeña agricultura en lo esencial incluyen y se limitan a: 1) innovación tecnológica; 2) servicios de asistencia técnica, legal y contable en la gestión empresarial individual y asociativa; 3) asociatividad económica nivel local y territorial; 4) acceso a mercados y comercialización; 5) acceso al financiamiento de capital de trabajo e inversiones; 6) conservación y manejo de recursos naturales; 7) en algunos casos, pero no siempre, inversión en infraestructura comunitaria y predial de relativamente bajo costo y complejidad — sistemas de riego tecnificado, acopio y bodegajes, pools de maquinaria agrícola, etc.- . Lo anterior, por supuesto que no impide que los pequeños productores accedan a los servicios de programas generales de sanidad animal y vegetal, ciencia y tecnología, información de mercados, promoción de exportaciones, entre otros.

d) Diseños flexibles que se puedan adecuar a las muy diversas realidades y necesidades locales, lo que usualmente se combina con un enfoque territorial en la implementación de los programas.

e) Aunque hay recursos que se ejecutan mediante el procedimiento de atención a la demanda recibida en ventanilla, los países más 


\section{Héctor Robles Berlanga La pequeña agricultura campesina y familiar: construyendo una propuesta...}

avanzados en sus políticas de pequeña agricultura — por ejemplo, Brasil y Chile, al igual que los europeos, o Nueva Zelanda y Australia - suelen identificar la población y territorio a atender con base en indicadores que expresan los objetivos de la política pública, para luego en cada territorio definir un programa o proyecto para un número importante de productores, que utiliza en forma articulada varios o todos los componentes señalados en el apartado c).

f) La prestación de los servicios a los productores en cada proyecto territorial en muchos casos se deja en manos de prestadores no gubernamentales — despachos de profesionistas, ONG, departamentos técnicos de organizaciones de productores, etcétera.

\section{Algunos apuntes para un programa de agricultura en pequeña escala}

El problema central que enfrenta la pequeña agricultura es una baja productividad 5 que reduce su rentabilidad y competitividad económica y limita los ingresos generados para el bienestar del hogar. La productividad económica de los pequeños productores es baja debido a:

- Escaso acceso a tecnologías, capacitación, asistencia técnica e información, lo que se traduce en lentos procesos de innovación tecnológica.

- Muy bajos niveles de participación en organizaciones económicas locales y territoriales eficaces, sustentables y sujetas al control de los pequeños productores que las integran, lo que les impide tener economías de escala para la producción, la comercialización y el acceso a bienes y servicios públicos y privados.

-Escaso acceso a servicios financieros, incluyendo crédito para capital de trabajo y para inversiones productivas, seguros y otros instrumentos de gestión de riesgos climáticos y económicos.

\footnotetext{
${ }^{5}$ Aunque hay formas más precisas de medir la productividad económica, para fines del Programa Piloto Territorios Productivos, ésta se entiende como el valor agregado agropecuario por unidad de trabajo. Véase Berdegué et al., 2015, Territorios productivos: un programa articulador para reducir la pobreza rural a través del incremento de la productividad, la producción y los ingresos, Rimisp, Santiago de Chile.
} 
- Débil participación en los mercados y en las cadenas de valor más dinámicas y rentables, y posición sumamente desventajosa en las relaciones con otros agentes de mercado - intermediarios, mayoristas, agroindustrias, supermercados, etcétera.

- Escasa capacidad de gestión empresarial por bajos niveles educacionales y nulo acceso a servicios de asesoría contable, legal, y de gestión y administración.

- Deterioro de sus recursos naturales, casi nulo acceso a bienes y servicios para su gestión sustentable y conservación, muy insuficiente inversión en sistemas de riego que los deja sujetos a la producción de temporal, y ausencia de servicios de apoyo para implementar estrategias y prácticas de adaptación al cambio climático.

- Posición pasiva y subordinada en los sistemas y mecanismos formales e informales de acceso a los programas públicos de fomento productivo.

El objetivo del programa que se propone para atender al productor de pequeña escala es que las Unidades Económicas Rurales en localidades de alta y muy alta marginación aumenten sus ingresos obtenidos a través de sus actividades económicas agropecuarias, su producción de alimentos, la productividad de los factores de producción de que disponen y que accedan efectivamente a las políticas y programas públicos para los cuales califican.

El tamaño del sector de la pequeña agricultura varía de acuerdo con diferentes definiciones. Según Sagarpa-FAO (2012), está integrada por $4,859,489$ Unidades, de las cuales $80 \%$ es de subsistencia - estratos I y II de la tipología del estudio citado- - en tanto que el resto se divide casi por igual en un estrato "en transición" y otro de tipo "empresarial con rentabilidad frágil”.

Robles y Berdegué (2015) toman directamente los datos del Censo Agropecuario y señalan que en el país hay 3.7 millones de unidades productivas con 20 hectáreas o menos que reportaron actividad agropecuaria y forestal. ${ }^{6}$ Estas unidades productivas cuentan con poco

\footnotetext{
${ }^{6}$ Sin considerar que tengan o no actividad productiva, hay 4,984,209 Unidades de menos de 20 ha — con 20.4 millones de hectáreas_ número muy similar al del estudio
} 


\section{Héctor Robles Berlanga La pequeña agricultura campesina y familiar: construyendo una propuesta...}

más de 15 millones de hectáreas. De acuerdo con el Censo Agrícola, Ganadero y Forestal 2007, el alcance potencial del programa está integrado por 3.7 millones de unidades económicas rurales de hasta 20 hectáreas en las cuales hay actividad agropecuaria o forestal. La población objetivo del programa estaría conformada por 1,050,571 hogares de pequeños productores que operan unidades económicas rurales de hasta 20 hectáreas de superficie, en 42,974 localidades de alta y muy alta marginación y que son derechohabientes de Prospera. ${ }^{7}$

El modelo de intervención se movería bajo cinco ejes: a) Innovación tecnológica; b) organización económica para la producción; c) desarrollo de capacidades; d) comercialización, y e) inclusión financiera y de seguros. La posibilidad de articular estos servicios en apoyo a las actividades productivas en los territorios rurales fortalecería las capacidades productivas y se construirían sinergias desde los espacios rurales evitando duplicidades.

La experiencia internacional señala que para tener éxito en los programas de apoyo a la pequeña agricultura deben incluir varios componentes articulados entre sí, que han de retomarse en la reformulación del Programa de Apoyo a Pequeños Productores con clave presupuestal S266 que empezó a operar en 2016.

De acuerdo con Soto Baquero (op. cit.), estos componentes son:

- Innovación tecnológica. Para mejorar la productividad de este sector. En consecuencia se requiere de un tipo de investigación científico tecnológica de carácter público que sea capaz de valorar los recursos y las condiciones locales. Por ello debe incorporar el uso de semillas -básica, registrada, mejorada, y común- como factor estratégico para el aumento de la productividad en la pequeña agricultura. Además, generar activos - maquinaria - que respondan a este tipo de agricultura.

\footnotetext{
Sagarpa-FAO (2012).

${ }^{7}$ La población objetivo, por extensión de la definición, incluye a las personas integrantes de dichos hogares, así como a los grupos y organizaciones formales e informales integrados predominantemente por personas y hogares que cumplen con los criterios de elegibilidad señalados.
} 


\section{Héctor Robles Berlanga La pequeña agricultura campesina y familiar: construyendo una propuesta...}

- Organización económica. La adopción de innovaciones tecnológicas, el mejoramiento en la calidad de los productos y el acceso a mercados depende en gran medida de lograr escalas mínimas de producción, disminuir las asimetrías de información y aumentar las capacidades de negociación en las cadenas agroalimentarias. ${ }^{8}$

- Desarrollo de capacidades. Tanto la efectividad de las medidas gubernamentales de distribución de semillas o insumos, para aumentar la producción de alimentos en el corto plazo, como el acceso a la tecnología de los pequeños agricultores, depende esencialmente, en el medio y largo plazo, de un eficiente sistema de extensionismo.

- Comercialización. En muchas ocasiones la falta de una demanda efectiva a precios atractivos constituye un factor que reduce las expectativas de siembra, más allá del autoconsumo, de los pequeños agricultores. Esto es particularmente válido en lugares donde los mercados de productos no funcionan adecuadamente, sea por deficiencias en la infraestructura o por una concentración en el poder comprador a nivel de los sistemas de comercialización.

-Inclusión financiera. Más que crédito agrícola, los pequeños agricultores requieren de servicios financieros que respondan a las estrategias económicas de los hogares rurales.

El diseño de la intervención que propone la campaña Valor al Campesino para operar el Programa S266 en 2017 se basa en las siguientes estrategias:

1. Articulación de componentes. A diferencia de otros programas cuyos componentes operan independientes uno de otro al punto de que tienen distintas poblaciones atendidas, en este programa todos los

8 Estamos hablando de organizaciones económicas que se caractericen por la participación responsable, activa y consciente de cada uno de los miembros en las actividades, aportaciones, estrategias y objetivos de la organización; ejercitando sus derechos y cumpliendo sus obligaciones. Además, basado en la participación consciente de cada uno de los integrantes; respeta la libertad individual; otorga el poder de autoridad a la mayoría sobre la minoría y respeta la opinión de ésta, en donde sus miembros tengan una actitud individual y humanista que refleje capacidad de integración a una causa común, asumiendo responsabilidades y compartiendo intereses y dificultades de los demás. 


\section{Héctor Robles Berlanga La pequeña agricultura campesina y familiar: construyendo una propuesta...}

componentes convergen en un mismo conjunto de personas atendidas. Cada participante recibe por tanto un conjunto integral de componentes, que trabajan articuladamente para resolver entre todos los principales estrangulamientos que limitan la productividad económicas de estos productores. Existirá una sola regla de operación y un solo sistema para ingresar, evaluar, y aprobar o rechazar los proyectos integrales multicomponentes presentados por los participantes. De esta forma, los componentes serán efectivamente eso, partes integrantes de un solo programa con un mismo grupo de beneficiarios y con un solo fin y propósito.

2. Enfoque territorial e integral. A diferencia de otros programas que entregan sus recursos por ventanilla y los asignan a familias individuales o pequeños grupos de familias o personas, sin continuidad temporal, este programa identificará ex ante territorios - conjuntos de localidades - en los municipios de alta y muy alta marginación de los diez estados incluidos. En estos territorios, se elaborarán proyectos integrales de desarrollo con todos los pequeños productores elegibles ahí residentes que expresen su interés en participar. Dichos proyectos deberán incluir todos los componentes que sean pertinentes para los problemas y oportunidades que tengan los productores participantes. Los proyectos se diseñarán con un horizonte temporal de tres a cinco años, aunque el compromiso del gobierno de financiarlos deberá renovarse anualmente de acuerdo con lo autorizado para el programa en el Presupuesto de Egresos de la Federación (PEF) respectivo. De haber recursos autorizados, se dará prioridad a continuar los proyectos ya vigentes por el tiempo necesario para que los pequeños productores efectivamente hayan aumentado su productividad y adquirido las condiciones y capacidades necesarias para mantener en el tiempo sus procesos de desarrollo.

3. Centrado en el desarrollo de la población objetivo. A diferencia de otros programas que en sus definiciones declaran hectáreas, cabezas de ganado, proyectos realizados, etc., este programa atiende a pequeños productores en localidades de alta y muy alta marginación. Sus objetivos e indicadores de resultados se definen como cambios 


\section{Héctor Robles Berlanga La pequeña agricultura campesina y familiar: construyendo una propuesta...}

positivos en las capacidades y resultados de estas personas en su condición de agentes económicos.

4. Promoción de la organización económica. A través del componente 2, el programa promoverá el desarrollo de organizaciones económicas reales, sujetas al control de sus miembros, y cuyas tareas y objetivos no se limiten a las actividades del programa sino también a consolidar formas asociativas que perduren en el tiempo y que sean un activo permanente de los pequeńos productores.

5. Desarrollo de capacidades. A través del componente 1 , se prestará a los pequeños productores un servicio de acompañamiento para generar procesos organizativos, identificar necesidades de capacitación y posibles proyectos complementarios de desarrollo.

6. Responsabilidad social. Se propone la firma de convenios entre organizaciones locales y gobierno que permitan el desarrollo de planes regionales, el impulso de proyectos territoriales y el compromiso en el buen uso de los recursos. Esto generaría corresponsabilidad entre las Unidades Económicas Rurales y su contraparte.

Con base en estas estrategias, el proceso de atención puede resumirse de la siguiente forma, teniendo en cuenta que en el año 1 el programa debe instalarse en cada una de las localidades y municipios participantes.

- La unidad de intervención será un territorio, definido como un grupo de localidades vecinas con población a atender, en lo posible vinculadas a un mismo centro urbano en el cual los pequeños productores realicen sus procesos comerciales, administrativos, de acceso a servicios, etc. Para facilitar la interacción con los gobiernos locales en lo que sea conveniente para el fin del programa, se propondrá que estos territorios estén íntegramente comprendidos dentro de los límites de un solo municipio. Para que el programa sea costo-eficiente y además pueda aspirar a lograr cierta masa crítica de resultados e impactos, evitando la dispersión y atomización de esfuerzos, se intentará que cada territorio tenga una población a atender de unas 500 personas, ${ }^{9}$ aproximadamente. De esta forma un

\footnotetext{
${ }^{9}$ El número de 500 personas se retoma de la experiencia del Programa Piloto Territorios
} 


\section{Héctor Robles Berlanga La pequeña agricultura campesina y familiar: construyendo una propuesta...}

municipio podrá tener uno o más territorios dentro del programa. La delimitación de estos territorios en cada municipio es una tarea a realizar en los meses finales del año anterior y al inicio del año que se lleve a cabo la propuesta se tendrá ya un mapa de cada entidad federativa con una lista completa de la población a atender por territorio.

- En los primeros seis meses del programa se deben lograr tres resultados iniciales, con base en los cuales el programa estará en condiciones de comenzar a dar servicios a los pequeños productores. Estos resultados iniciales, de instalación del programa, son: a) se define por concurso público un prestador de servicios responsable de la implementación del programa; b) el prestador de servicios, en diálogo y con la participación efectiva de la población a atender, formula un proyecto integral de desarrollo de la pequeña agricultura en el territorio; c) la población a atender se informa sobre el proyecto integral que se le propone, así como de sus derechos y deberes como participantes en el programa, y con base en dicha información, ratifica su voluntad de participar en el programa, conformando de esa forma el padrón de derechohabientes en ese territorio. Estas tres tareas con sus respectivos resultados requieren seis meses efectivos de trabajo desde el momento en que se inicie la operación del programa. ${ }^{10}$

- Los prestadores de servicios pueden incluir a universidades y otras instituciones de educación superior, organizaciones campesinas, Ong y despachos privados. La selección de los prestadores de servicios se hará por concurso público, con base en dos criterios: a) la calidad de los integrantes del equipo técnico que el postulante se compromete a contratar, todos ellos con residencia en la ciudad de 15,000 o más habitantes más próxima al territorio; b) el perfil de proyecto que el postulante presente al concurso y su pertinencia dadas las características socioeconómicos, biofísicas y agropecuarias del territorio y de

Productivos donde se señala que debe existir una masa crítica de participantes para poder emprender actividades económicas con cierto éxito. Véase Berdegué, Franco, Gordillo, Robles, Scott, Soloaga, Toledo y Yúnez (op. cit.).

${ }^{10}$ Si bien el programa nominalmente se inicia en enero 2016, en realidad la ejecución requiere que se hayan liberado los recursos del presupuesto 2016 para que la dependencia a cargo pueda efectivamente comenzar a operar. 
sus pequeños productores. Un mismo prestador de servicios puede concursar para atender uno o más territorios de un mismo municipio o de municipios vecinos dentro de cada entidad federativa.

- Una vez que el prestador de servicios se haya contratado y la población a atender haya manifestado su acuerdo de participar, se procederá a la preparación de los proyectos integrales de desarrollo. Cada proyecto en principio deberá integrar los cuatro componentes del programa, definiendo los problemas, objetivos y resultados a lograr, y las acciones principales en cada componente. Un componente podrá estar ausente solamente en aquellos casos — muy improbables, si es que existen - en que se concluya fundadamente que no existe ningún problema relevante o ningún objetivo importante a lograr, en materia de innovación tecnológica y producción, asociatividad económica, acceso a mercados y comercialización, o articulación con otros programas y actores públicos y privados. Los proyectos se diseñarán con un horizonte temporal de tres a cinco años, dejándose expresamente señalado que la continuidad año tras año del programa estará sujeta a los presupuestos de egresos de la Federación. Sin embargo, si el presupuesto se mantiene, el programa asegurará la continuidad en cada territorio antes de incorporar a nuevos beneficiarios, al menos hasta completar el periodo del proyecto. Al término de este periodo, el programa podrá ofrecer a la población atendida en el territorio una oportunidad de continuar el proceso de desarrollo con base en un nuevo proyecto, sí y solo sí los resultados hasta entonces obtenidos justifican la continuidad de la atención.

- Se debe definir una estrategia de seguimiento y evaluación del programa, en diálogo con Coneval y con la Unidad de Productividad Económica de la Secretaría de Hacienda y Crédito Público. Dicha estrategia deberá incluir los procesos requeridos para poder evaluar con rigurosidad los resultados e impactos de dicho programa. ${ }^{11}$

11 CIESAS realizó la Evaluación de Diseño del Programa de Apoyo a Pequeños Productores que impulsó la Secretaría de Agricultura, Ganadería, Desarrollo rural, Pesca y Alimentación, y no la estrategia integral que propuso la campaña Valor al Campesino; ésta no fue retomada por el gobierno mexicano. 
En junio de 2016, CIESAS realizó la Evaluación de Diseño del Programa de Apoyo a Pequeños Productores. misma que arroja de manera sintética los siguientes resultados: a) no se establece cuál es la vinculación directa entre los pequeños productores y la Población Objetivo definida en el diagnóstico del programa ni en la normatividad aplicable de ambos programas; b) Se encontró que dicha estratificación se basa en una metodología que se fundamenta en el indicador proxi "bajo ingreso anual de las unidades económicas rurales", que no mide de manera adecuada la productividad pues no se basa en los rendimientos o la eficiencia en el uso de los recursos; c) la definición de PO no está en posibilidad de cumplir lo que señala el Art. 75 de la Ley Federal de Responsabilidad Hacendaria respecto de identificar con precisión la PO, tanto por grupo específico como por región del país, entidad y municipio, y d) la heterogeneidad de la PO y sus componentes no permite identificar de forma clara que pertenezcan a un mismo universo en función del problema identificado y que cumplan una condición indispensable: que sean pequeños productores (CIESAS, 2016).

La campaña Valor al Campesino retomó los resultados de la evaluación para solicitar cambios al programa en 2017. Lo presenta de manera resumida en la siguiente infografía: 


\section{¿OTRO AÑO DE SIMULACIÓN EN SAGARPA O CAMBIO REAL PARA 2017?}

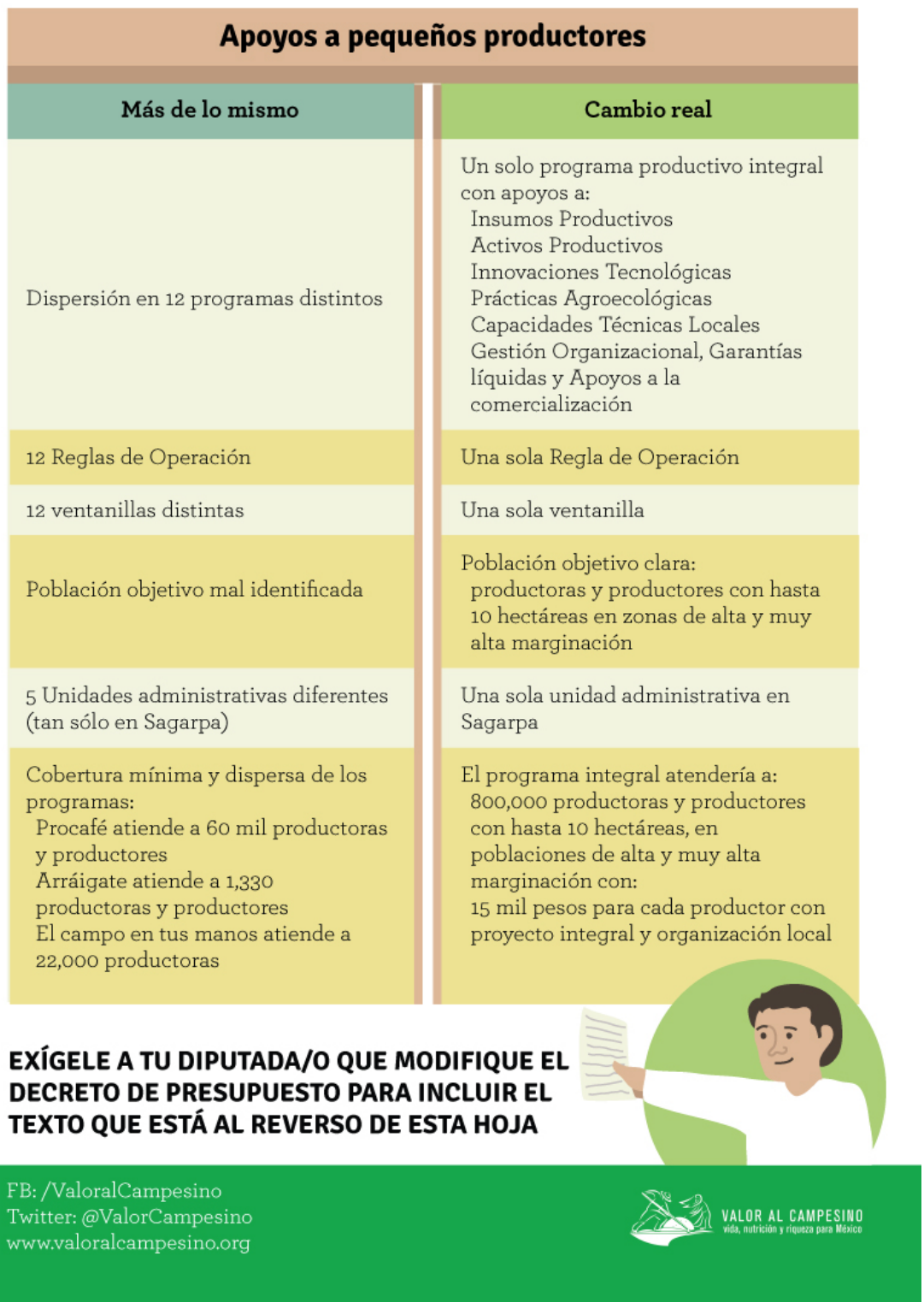


La campaña Valor al Campesino, además de todas las características señaladas con anterioridad que debería incluir el Programa de Apoyo a Pequeños Productores en 2017, propone que se consideren los siguientes elementos:

- Inclusión Financiera. ${ }^{12}$ Mediante el componente de articulación, se buscará aprovechar las transferencias del Proagro Productivo y Progan, como garantías líquidas para que los pequeños productores puedan acceder al financiamiento y potenciar los apoyos. A los servicios de financiamiento se debe agregar el tema del seguro agrícola, especialmente con los efectos actuales del cambio climático que genera siniestralidad recurrente.

- Una sola Regla de Operación (ROP). Se propone hacer el esfuerzo de articular las reglas de operación del S266 con otros programas de propósitos similares existentes en la administración pública federal con la finalidad de articular la atención a los pequeños productores. La articulación se debe reflejar en las distintas ROP con planteamientos comunes o similares referente a propósitos, poblaciones a atender, requisitos, tipo de beneficiarios e incentivos complementarios.

- Compras gubernamentales en apoyo a pequeños productores y al fortalecimiento de los mercados regionales. El gobierno mexicano tiene programas de desayunos escolares, de comedores comunitarios, de abasto a sectores vulnerables, entre otros. Si parte de los productos que requiere para elaborar alimentos los comprara directamente a quienes los producen, permitiría dar certeza a los productores, garantizaría un ingreso y dinamizaría las economías locales.

- Experimentación de modalidades de atención a pequeños productores. Finalmente, y como ya se ha indicado, sólo una cuarta parte de la población objetivo podrá ser atendida en los primeros años del programa, por restricciones presupuestarias y, también, porque la construcción de capacidades institucionales y técnicas para atender

${ }^{12}$ Respecto a este tema ya se tiene el antecedente del Programa Integral de Inclusión Financiera que brinda a las familias beneficiarias de Prospera y del Programa Alimentario (PAL) acceso en condiciones preferenciales a un conjunto de servicios y productos financieros formales a través de educación financiera, instrumentos de ahorro, cobertura de seguro de vida, instrumentos básicos y complementarios de crédito y paquetes de beneficios adicionales. En esta acción tiene una participación relevante Bansefi. 
una población mayor es un proceso gradual que no se podrá realizar en uno o dos años. Este hecho permite considerar la posibilidad de implementar un diseño experimental que durante tres o cuatro ańos ponga a prueba tres formas de relación con los pequeños productores: a) pequeños productores que siendo elegibles no pueden ser atendidos por restricciones presupuestarias; b) pequeños productores elegibles que son atendidos con la modalidad de ventanilla de pequeños proyectos familiares o multifamiliares, utilizada por la gran mayoría de los programas productivos; c) pequeños productores elegibles que son atendidos con la modalidad de proyectos productivos integrales de escala territorial, como se propone para este programa. 


\section{Bibliografía citada}

Aserca, "Las tendencias en la agricultura a pequeña escala y en los mercados de productos agroalimentarios", en http://www. infoaserca.gob.mx/claridades/revistas/244/ca244-7.pdf

Ashoka, Fundar, Fundación Semillas de Vida, Asociación Nacional de Empresas Comercializadoras de Productores del Campo, Poder del Consumidor, Subsidios al campo México, 2015, Iniciativa Valor al campesino. Vida, nutrición y riqueza para México, México (mimeo).

Banco Mundial, 2014, "Agricultura: Resultados del sector. Un motor para el crecimiento sostenible y la reducción de la pobreza”, en http://www.bancomundial.org/es/results/2013/04/15/agriculture-results-profile

Berdegué Julio y Ricardo Fuentealba, 2014, “De promesas a prioridades. Poniendo a la agricultura familiar y campesina al centro de un sistema de producción de alimentos justo en América Latina y el Caribe”, Nota informativa de OXFAM, 23 de julio de 2014. Berdegué Julio, Gerardo Franco, Gustavo Gordillo, Héctor Robles, John Scott, Isidro Soloaga, Carlos Toledo y Antonio Yúnez, 2015, Territorios productivos: Un Programa Articulador para Reducir la Pobreza Rural a través del Incremento de la Productividad, la Producción y los Ingresos, Rimisp, Santiago de Chile.

CIESAS, 2016, Evaluación de Diseño del Programa de Apoyo a Pequeños Productores S266, Coneval/CIESAS, México.

Coneval, 2013, Pobreza 2012, Resultados de pobreza a nivel nacional y por entidades federativas 2010-2012, Coneval, México.

Ensanut, 2012, Encuesta Nacional de Salud y Nutrición, México.

FAO, 2009, Cómo alimentar al mundo en 2015, FAO, Roma.

FAO, Hojas de Balance 1961-2011, en http://faostat3.fao.org FAO, 2014, "Año Internacional de la Agricultura Familiar", FAO, Roma. Gasselin, Pierre, Benoît Dedieu y Hervé Guyomard, 2015, "Hay que valorar mejor las ventajas de la agricultura familiar", La Jornada del Campo, núm. 95, 15 de agosto de 2015, México.

Gobierno de la República, 2013, Programa para Democratizar la Productividad 2013-2018, DOF, 30 de agosto de 2013. 
Gobierno de la República, 2013, Programa Nacional de Desarrollo Agropecuario, Pesquero y Alimentario 2013-2018, DOF, 13 de diciembre de 2013.

HLPE, 2013, "Inversión en la agricultura a pequeña escala en favor de la seguridad alimentaria", Informe del Grupo de Alto Nivel de Expertos en Seguridad Alimentaria y Nutrición del Comité de Seguridad Alimentaria Mundial, Roma, páginas 7-11.

Instituto Nacional de Estadística y Geografía, 1930, I Censo Agrícola Ganadero 1930, Tabulados, México.

Instituto Nacional de Estadística y Geografía, 1940, II Censo Agrícola, Ganadero y Forestal 1940, Tabulados, México.

Instituto Nacional de Estadística y Geografía, 1950, III Censo Agrícola Ganadero y Forestal 1950, Tabulados, México.

Instituto Nacional de Estadística y Geografía, 1960, IV Censo Agrícola Ganadero y Forestal 1960, Tabulados, México.

Instituto Nacional de Estadística y Geografía, 1970, V Censo Agrícola Ganadero y Forestal 1970, Tabulados, México.

Instituto Nacional de Estadística y Geografía, 1990, VII Censo Agrícola Ganadero y Forestal 1990, Tabulados, México.

Instituto Nacional de Estadística y Geografía, 2007, Censo Agrícola Ganadero y Forestal 2007, Tabulados, México.

Maluf, Renato, 2010, "Seguridad alimentaria como un objetivo estratégico para el país. En el Rol de la agricultura familiar en el desarrollo y la seguridad alimentaria”, Revista IICA, núm. 5, diciembre de 2010, Uruguay.

OCDE, Organización para la Cooperación y Desarrollo Económicos, 2011, "Análisis del extensionismo agrícola”, texto completo, en http://www.sagarpa.gob.mx/desarrolloRural/Documents/ EXTENSION IS M O / ES T U D I O \% 20 OCD E \% 20 EXTENSIONSMO.pdf, consultado en agosto 2013.

Ramilo, Diego, 2010, "El desafío es generar tecnologías apropiadas para la AF. En el rol de la agricultura familiar en el desarrollo y la seguridad alimentaria”, Revista IICA, núm. 5, diciembre de 2010, Uruguay. 
Red GTD, 2014, Exposición de motivos del Congreso Internacional Gestión Territorial del Desarrollo, realizado los días 3, 4 y 5 de diciembre, Cocoyoc, Morelos, México.

Robles, Héctor, 2007, El sector rural en el siglo XXI. Un mundo de realidades y posibilidades, CEDRSSA, México.

Robles, Héctor, 2012, "El caso de México”, En Fernando Soto Baquero y Sergio Gómez (editores), Dinámicas del mercado de la tierra en América Latina y el Caribe: concentración y extranjerización, FAO, Roma.

Robles, Héctor y Julio Berdegué, 2015, “Matriz de Indicadores para Resultados del programa S266”, Programa de Apoyo a Pequeños Productores, Rimisp, México.

Sagarpa-FAO, 2012, Diagnóstico del sector rural y pesquero de México 2012, Sagarpa/FAO.

Sánches, Adoniram, 2010, "La agricultura no es planeada aisladamente", Revista IICA, núm. 5, diciembre de 2010, Uruguay.

Sarukhán, J. et al., 2008, Capital natural de México. Sintesis: conocimiento actual, evaluación y perspectivas de sustentabilidad, Comisión Nacional para el Conocimiento y Uso de la Biodiversidad, México.

Schejtman y Chiriboga, 2009, “Desarrollo Territorial Soberanía y Seguridad Alimentaria”, Documento de Trabajo núm. 62, Programa Dinámicas Territoriales Rurales Rimisp-Centro Latinoamericano para el Desarrollo Rural, Santiago de Chile.

Soto Baquero, Fernando, 2008, Políticas públicas y la nueva situación en los precios internacionales de los alimentos, FAO, Roma.

Unesco, 2010, La cocina tradicional mexicana, cultura comunitaria, ancestralyviva-Elparadigma de Michoacán, en http://www.unesco. org/culture/ich/index.php?lg=es\&pg=00011\&RL=00400

Ventura, L., 2012, "El derecho a la autodeterminación de los pueblos indígenas: marco para construir las estrategias de cooperación”, en García, C., P. Gil y P. Sanchiz, 2012, Las políticas de desarrollo y cooperación de las ONG en América Latina, Universidad de Sevilla, Sevilla. 